\title{
Genotype-Dependent Tumor Regression in Marek's Disease Mediated at the Level of Tumor Immunity
}

\author{
Shyamesh Kumar • Joram J. Buza $\cdot$ Shane C. Burgess
}

Received: 26 August 2008 / Accepted: 14 December 2008 /Published online: 18 March 2009

(C) The Author(s) 2009. This article is published with open access at Springerlink.com

\begin{abstract}
Marek's disease (MD) of chickens is a unique natural model of Hodgkin's and Non Hodgkin's lymphomas in which the neoplastically-transformed cells over-express $\mathrm{CD} 30\left(\mathrm{CD} 30^{\mathrm{hi}}\right)$ antigen. All chicken genotypes can be infected with MD virus and develop microscopic lymphomas. From 21 days post infection (dpi) microscopic lymphomas regress in resistant chickens but, in contrast, they progress to gross lymphomas in susceptible chickens. Here we test our hypothesis that in resistant chickens at $21 \mathrm{dpi}$ the tissue microenvironment is pro T-helper (Th)-1 and compatible with cytotoxic T lymphocyte (CTL) immunity but in susceptible lines it is pro Th-2 or pro T-regulatory (T-reg) and antagonistic to CTL immunity. We used the B2, non-MHC-associated, MD resistance/susceptibility system (line $[\mathrm{L}] 6_{1} /$ line $[\mathrm{L}] 7_{2}$ ) and quantified the levels of key mRNAs that can be used to define Th-1 (IL-2, IL-12, IL-18, IFN $\gamma$ ), Th-2 (IL-4, IL-10) and T-reg (TGF $\beta$, GPR-83, CTLA-4, SMAD-7) lymphocyte phenotypes. We measured gene expression in both whole tissues (represents tissue
\end{abstract}

S. Kumar $(\bowtie) \cdot$ S. C. Burgess

College of Veterinary Medicine,

Box 6100, Starkville, MS 39762, USA

e-mail: skumar@cvm.msstate.edu

S. Kumar • S. C. Burgess

Mississippi State University Institute for Digital Biology,

Starkville, MS, USA

S. C. Burgess

Life Sciences and Biotechnology Institute,

Mississippi State University,

Starkville, MS 39762, USA

\section{J. J. Buza}

School of Veterinary Medicine,

Department of Comparative Pathobiology, Purdue University,

West Lafayette, IN 47907, USA microenvironment and tumor microenvironment) and in the lymphoma lesions (tumor microenvironment) themselves. Gene ontology-based modeling of our results shows that the dominant phenotype in whole tissue as well as in microscopic lymphoma lesions, is pro T-reg in both $\mathrm{L}_{1}$ and $\mathrm{L} 7_{2}$ but a minor pro Th- 1 and anti Th- 2 tissue microenvironment exists in L6 $6_{1}$ whereas there is an anti Th- 1 and pro Th- 2 tissue microenvironment in $\mathrm{L}_{2}$. The tumor microenvironment per $s e$ is pro T-reg, anti Th-1 and pro Th-2 in both $\mathrm{L} 6_{1}$ and $\mathrm{L} 7_{2}$. Together our data suggests that the neoplastic transformation is essentially the same in both $\mathrm{L}_{1}$ and $\mathrm{L}_{2}$ and that resistance/susceptibility is mediated at the level of tumor immunity in the tissues.

Keywords Animal model · Gene ontology · Herpesvirus . Lymphoma $\cdot$ Microenvironment $\cdot$ Regulatory T cell

$\begin{array}{ll}\text { Abbreviations } \\ \text { ADOL } & \text { Avian disease oncology laboratory } \\ \text { cHL } & \text { Classical Hodgkin's lymphoma } \\ \text { CTL } & \text { Cytotoxic T lymphocyte } \\ \text { CTLA } & \text { Cytotoxic T-lymphocyte associated antigen } \\ \text { C }_{t} & \text { Cycle threshold } \\ \text { CVM- } & \text { College of Veterinary Medicine-Mississippi } \\ \text { MSU } & \text { State University } \\ \text { DPI } & \text { Days post infection } \\ \text { FOX } & \text { Forkhead box protein } \\ \text { GO } & \text { Gene ontology } \\ \text { GPR } & \text { G protein-coupled receptor } \\ \text { HL } & \text { Hodgkin's lymphoma } \\ \text { IFN } & \text { Interferon } \\ \text { IL } & \text { Interleukin } \\ \text { L } & \text { Line } \\ \text { LCM } & \text { Laser capture microdissection } \\ \text { MD } & \text { Marek's Disease }\end{array}$




\begin{tabular}{|c|c|}
\hline MDV & Marek's Disease virus \\
\hline NHL & Non Hodgkin's lymphoma \\
\hline NO & Nitric oxide \\
\hline QPCR & $\begin{array}{l}\text { Duplex reverse transcriptase real-time } \\
\text { polymerase chain reaction }\end{array}$ \\
\hline SEM & Standard error of mean \\
\hline SMAD & Small mothers against decapentaplegic \\
\hline SPF & Specific pathogen free \\
\hline Th & T helper \\
\hline T-reg & Regulatory $\mathrm{T}$ cell \\
\hline TNSFR & $\begin{array}{l}\text { Tumor necrosis factor receptor superfamily } \\
\text { member }\end{array}$ \\
\hline TRAF & Tumor necrosis factor receptor associated factor \\
\hline USDA & United States Department of Agriculture \\
\hline
\end{tabular}

\section{Introduction}

Lymphomas are the $6^{\text {th }}$ leading cause of death due to cancer, 4th greatest in economic impact and they account for $53 \%$ of the new cases of hematological malignancies in the USA [1]. It is imperative to understand the complex dynamics of host-tumor interactions within the tumor microenvironment for designing any anti-tumor strategy. To do so requires animal models, which fully mimic human tumor microenvironment and where both tumor and stromal cells can be studied within the natural tumor environment [2]. Marek's Disease (MD) is a lymphomatous disease of chickens caused by the MD $\alpha$-herpesvirus (MDV) and is a unique natural model for human Hodgkin's (HL) and nonHodgkin's lymphomas (NHL) which overexpress CD30 $\left(\mathrm{CD} 30^{\text {hi }}\right.$; a.k.a. tumor necrosis receptor superfamily member [TNSFR-8] or the "Hodgkin's disease antigen") [3]. $\mathrm{MD}$ is a general model for $\mathrm{CD} 30^{\mathrm{hi}} \mathrm{T}$ cell lymphomas which includes anaplastic large cell lymphoma, primary cutaneous anaplastic large cell lymphoma, adult T-cell leukemia/ lymphoma, peripheral T-cell lymphoma, natural killer (NK)/T-cell lymphoma, nasal and enteropathy type $\mathrm{T}$ cell lymphoma [3, 4]. Like its human homologs, MD lymphomas are heterogeneous mixture of minority population of transformed cells $\left(\mathrm{CD} 30^{\mathrm{hi}}\right)$ surrounded by majority population of non transformed normal immune cells [5, 6]. However, MD transformed cells are not inherently immortal; they depend upon the local lymphoma environment for their survival and growth $[5,6]$.

MD has advantage over murine models of lymphoma as it provides an opportunity to study the phenomenon of genotype dependent tumor regression as a model of spontaneous human lymphoma regression [7]. All chicken genotypes are susceptible to MDV infection, neoplastic transformation and microscopic lymphoma development. However, from 21 days post infection (dpi) these micro- scopic lesions regress in MD resistant genotypes but progress to gross lymphomas in MD susceptible genotypes $[6,8]$. The fundamental genetic basis for the difference in lymphoma-regressing and progressing genotypes is poorly understood, though a very large body of work over almost 40 years has implicated several host immune factors, including innate cell-mediated immunity (CMI; including NK cells, monocytes); humoral, antigen-specific MHC class I-restricted cytotoxic T lymphocyte (CTL) immunity and cytokines (reviewed in [9]). At 21 dpi progressing lymphomas are $\mathrm{CD} 4+$ and $\mathrm{CD} 4+\mathrm{CD} 30^{\mathrm{hi}}$ predominant with few $\mathrm{CD} 8 \alpha+\mathrm{T}$ cells, whereas regressing lymphomas have many $\mathrm{CD} 8 \alpha+\mathrm{T}$ cells, fewer $\mathrm{CD} 4+\mathrm{CD} 30^{\mathrm{hi}}$ cells and the CD30 expression-though still above physiological levels in activated $\mathrm{T}$ cells [6]-is lower than in progressing lymphomas [8]. The neoplastically transformed MD lymphoma cells also have cytokine and other gene expression most similar to regulatory $\mathrm{CD} 4+\mathrm{T}$ lymphocytes (T-reg) [5].

Here we test our hypothesis that, at the pivotal $21 \mathrm{dpi}$ time point MD-resistant chicken genotypes have a tissue microenvironment congruent with CTL, where-as the tissue microenvironment in MD-susceptible genotypes is antagonistic to CTL. We tested this by quantifying the mRNAs for cytokines and other genes that determine T-helper (Th)-1; Th-2 and T-regulatory (T-reg) phenotypes: CD4+ Th-1 lymphocytes secrete high levels of interleukin (IL)-2 and interferon-gamma (IFN $\gamma$ ); CD4+ Th-2 lymphocytes secrete high levels of IL-4, IL-10 and IL-13 [10] and CD4+ T-reg lymphocytes express MHC II, transcription factor forkhead box protein (FOX) P3, G protein-coupled receptor (GPR)83 [11], IL-2 receptor $\alpha$ chain (CD25), high levels of cytotoxic T-lymphocyte associated antigen-4 (CTLA-4) [1215] and decreased small mothers against decapentaplegic-7 (SMAD-7) [16, 17].

We used the B2; non-MHC-associated MD resistance/ susceptibility (line $[\mathrm{L}] 6_{1} /$ line $[\mathrm{L}] 7_{2}$ ) system [8]. We analyzed the gene expression profiles at whole tissue level (which represents both tissue microenvironment and tumor microenvironment) and subsequently at the level of microscopic lesions (tumor microenvironment) using Laser Capture Microdissection (LCM). Our Gene Ontology (GO)-based hypothesis testing demonstrates that: 1. a T-reg phenotype exists in both the tissue and tumor microenvironments in both resistant and susceptible genotypes; 2 . a pro-inflammatory tissue microenvironment is present in both $\mathrm{L}_{1}$ and $\mathrm{L} 7_{2}$ tissues; 3 . an antiinflammatory and anti-CTL tumor microenvironment exists in microscopic lesions of both genotypes; 4. the susceptible genotype has an anti-CTL tissue microenvironment, whereas the resistant genotype has a pro-CTL tissue microenvironment. The fundamental differences between the genotypes exist at the level of the tissue 
immune response and not at the level of the transformed cells.

\section{Materials and Methods}

\section{Chickens, MDV and Tissue Sampling}

Day old, specific pathogen free (SPF), MDV maternal antibody negative, $\mathrm{L} 6_{1}$ and $\mathrm{L} 7_{2}$ chickens were obtained from United States Department of Agriculture-Avian Disease Oncology Laboratory (USDA-ADOL, East Lansing, Michigan). These chickens were double wing-banded, housed in small groups in separate cages in an isolation facility at College of Veterinary Medicine-Mississippi State University, (CVM-MSU). Food and water was provided ad libitum. All chickens were infected on day 14 with MDV (GA/22 strain; passage 18; 500 pfu; intra-abdominally) obtained from USDA-ADOL (East Lansing, MI). On 21 dpi, five $\mathrm{L}_{1}$ and five $\mathrm{L} 7_{2}$ chickens were selected using the random number function in Microsoft excel using the list of wing band numbers, killed, kidney lymphomas harvested (kidney had the most visible gross lymphomas), snap frozen in liquid nitrogen, vacuum sealed in plastic bags and stored at $-80^{\circ} \mathrm{C}$ until needed. All $\mathrm{L}_{2}$ birds that were not used for sampling developed gross lymphomas at later period and were euthanized. We confirmed that all chickens were MDV-infected by doing PCR on DNA isolated from the samples, using primers that amplify a fragment of the MDV Meq gene, exactly as described [8]. All animal practices and experiments were approved by the MSU-Institutional animal critical care and use committee.

Cryosectioning and Laser Capture Microdissection (LCM)

Tissue samples were transferred from $-80^{\circ} \mathrm{C}$ to a cryostat (Leica Microsystems Inc., Bannockburn, IL) on dry ice, and warmed to $-20^{\circ} \mathrm{C}$ before sectioning; $8 \mu \mathrm{m}$ cryosections were cut and placed directly into $1 \mathrm{ml}$ of TRI reagent (Molecular Research Center, Cincinnati, $\mathrm{OH}$ ) or onto Histogene LCM slides (Molecular Devices Sunnyvale, CA). Cryosections were stored (for no more than a week) at $-80^{\circ} \mathrm{C}$ until LCM. Cryosections were stained with Histogene Frozen Section Staining solution (Molecular Devices Sunnyvale, CA) following the manufacturer's protocol. Briefly, cryosections were ethanol fixed $(75 \%)$ for $30 \mathrm{~s}$, rehydrated in nuclease free water for $30 \mathrm{~s}$, stained with Histogene Staining solution $(100 \mu \mathrm{L}$ per slide for $20 \mathrm{~s}$ ), washed in nuclease free water for $30 \mathrm{~s}$ and dehydrated in $75 \%, 95 \%$ and $100 \%$ ethanol for $30 \mathrm{~s}$ each followed by final dehydration step in xylene for $5 \mathrm{~min}$ and allowed to air dry for $5 \mathrm{~min}$. Air dried
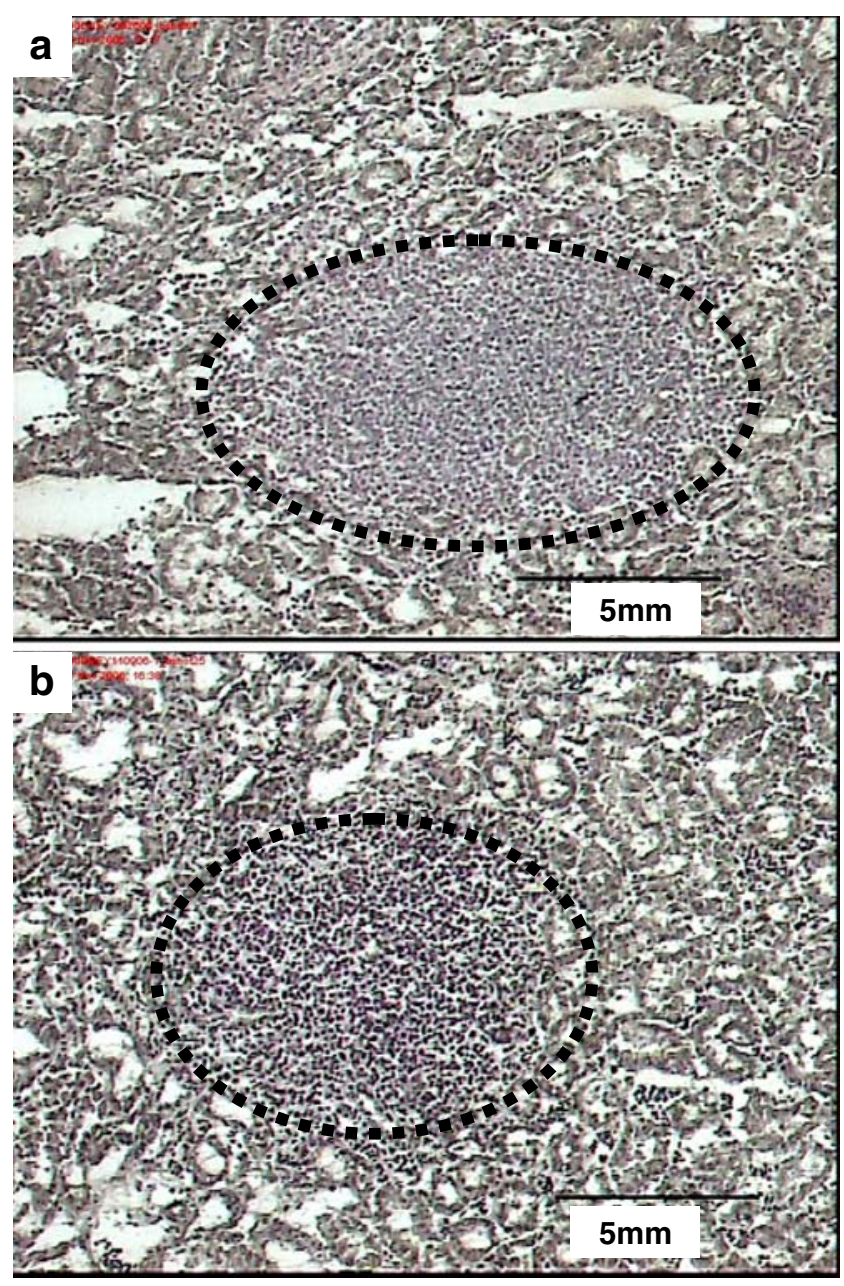

Fig. 1 Photomicrographs of kidneys at 21 dpi with MDV (see M\&M), stained with "Histogene LCM frozen section staining kit" showing similarity in size of microscopic lymphoma lesions (circled) between $\mathrm{L6}_{1}$ (a) and $\mathrm{L7}_{2}$ (b)

stained slides were placed in slide box with fresh desiccant and were used for LCM the same day. LCM was done using the PixCell IIe Laser Capture Microdissection system (Molecular Devices Sunnyvale, CA) and CapSure Macro LCM caps (Molecular Devices Sunnyvale, CA). MD microscopic lesions (Fig. 1a, b) were located and excised (laser power: $45-55 \mathrm{mw}$ for 3-5 ms). A new cap was used for each sample.

\section{RNA Isolation and Real-Time PCR}

Total RNA was isolated from $\sim 100 \mu \mathrm{g}$ of tissue sections using TRI reagent (Molecular Research Center, Cincinnati, $\mathrm{OH}$ ) exactly following manufacturer's protocol. Total RNA from each microdissected sample was isolated using the Pico Pure RNA isolation kit (Molecular Devices Sunnyvale, CA) exactly following the manufacturer's protocol. RNA concentrations were quantified (ND-1000 
spectrophotometer; NanoDrop Technologies, Wilmington, DE) and adjusted to within 10-fold concentration of each other using RNAase free water. For comparing mRNA expression, we used a duplex reverse transcriptase realtime PCR (QPCR), with 28S rRNA as a positive control for each PCR exactly as described [5]; iCycler iQ RealTime PCR Detection System [Bio-Rad Laboratories Inc., Hercules, CA]; Platinum Quantitative RT-PCR ThermoScript One-Step System [Invitrogen, Carlsbad, CA]; $100 \mathrm{pM}$ of each primer [except $28 \mathrm{~S}$ which was $1 \mathrm{pM}$ ]; $1 \mathrm{pM}$ of all probes; $2.5 \mu \mathrm{l}$ template RNA and RNAse free water; cycle conditions: $50^{\circ} \mathrm{C}, 30 \mathrm{~min} ; 95^{\circ} \mathrm{C}, 5 \mathrm{~min}+45 \times$ $\left.\left[95^{\circ} \mathrm{C}, 15 \mathrm{~s} ; 60^{\circ} \mathrm{C}, 60 \mathrm{~s}\right]\right)$. All primer and probe sequences (Table 1) are previously published and all amplicons (except 28S) cross intron-exon boundaries [5, 18-21]; although $28 \mathrm{~S}$ has no introns in it, it is routinely used as an internal control and its RNA template far exceeds its DNA template. Each QPCR experiment was done in triplicate and included no-template controls. Differences in the mean QPCR results were compared using one way analysis of variance.

Gene Ontology (GO) Based Quantitative Modeling

We tested our hypotheses using GO-based modeling of our QPCR data exactly as described [5]. Briefly, we used the computational tool GOmodeler [22], which scores the effects of each gene product on a process as either "pro" (+1), "anti" (-1), "no effect" (0) or "no data" (blank cell), then multiplies these score by the QPCR data for each gene. The net effect of each phenotype is the sum of scores of each gene for that phenotype and the net overall phenotype is the sum of scores of each phenotype.

Table 1 PCR probes and primers (fluorophore)

\begin{tabular}{|c|c|c|c|}
\hline RNA target & Probe/Primer & Sequence & Accession \\
\hline \multirow[t]{3}{*}{$28 \mathrm{~S}$} & Probe & 5'-(HEX)-AGGACCGCTACGGACCTCCACCA-(TAMRA)-3' & \multirow[t]{3}{*}{ X59733 } \\
\hline & $\mathrm{F}$ & 5'-GGCGAAGCCAGAGGAAACT-3' & \\
\hline & $\mathrm{R}$ & 5'-GACGACCGATTTGCACGTC-3' & \\
\hline \multirow[t]{3}{*}{ IL-2 } & Probe & 5'-(FAM)-ACTGAGACCCAGGAGTGCACCCAGC-(TAMRA)-3' & \multirow[t]{3}{*}{ AF221080 } \\
\hline & $\mathrm{F}$ & 5'-TTGGAAAATATCAAGAACAAGATTCATC-3' & \\
\hline & $\mathrm{R}$ & 5'-TCCCAGGTAACACTGCAGAGTTT-3' & \\
\hline \multirow[t]{3}{*}{ IL-4 } & Probe & 5'-(FAM)-AGCAGCACCTCCCTCAAGGCACC-(TAMRA)-3' & \multirow[t]{3}{*}{ NM_001007079 } \\
\hline & $\mathrm{F}$ & 5'-AACATGCGTCAGCTCCTGAAT-3' & \\
\hline & $\mathrm{R}$ & 5'-TCTGCTAGGAACTTCTCCATTGAA-3' & \\
\hline \multirow{3}{*}{ IL-10 } & Probe & 5'-(FAM)-CGACGATGCGGCGCTGTCA-(TAMRA)-3' & \multirow[t]{3}{*}{ AJ621614 } \\
\hline & $\mathrm{F}$ & 5'-CATGCTGCTGGGCCTGAA-3' & \\
\hline & $\mathrm{R}$ & 5'-CGTCTCCTTGATCTGCTTGATG-3' & \\
\hline \multirow[t]{3}{*}{ IL-12ß } & Probe & 5'-(FAM)-CTGAAAAGCTATAAAGAGCCAAGCAAGACGTTCT-(TAMRA)-3' & \multirow[t]{3}{*}{ AJ564201 } \\
\hline & & 5'-TGGGCAAATGATACGGTCAA-3' & \\
\hline & $\mathrm{F}$ & 5'-CAGAGTAGTTCTTTGCCTCACATTTT-3' & \\
\hline \multirow[t]{3}{*}{ IL-18 } & $\mathrm{R}$ & 5'-(FAM)-CCGCGCCTTCAGCAGGGATG-(TAMRA)-3' & \multirow[t]{3}{*}{ AJ276026 } \\
\hline & $\mathrm{F}$ & 5'-AGGTGAAATCTGGCAGTGGAAT-3' & \\
\hline & $\mathrm{R}$ & 5'-ACCTGGACGCTGAATGCAA-3' & \\
\hline \multirow[t]{3}{*}{ CTLA-4 } & Probe & 5'-(FAM)-TTGTCTTCTCTGAATCGCTTTGCCCACG-(TAMRA)-3 & \multirow[t]{3}{*}{ AM236874 } \\
\hline & $\mathrm{F}$ & 5'-CAGCATCATCATCTCAGCCATTG-3' & \\
\hline & $\mathrm{R}$ & 5'-GCATTTTCACATAGACCCCAGTAG-3' & \\
\hline \multirow[t]{3}{*}{ GPR-83 } & Probe & 5'-(FAM)-TCCGCCACCAGCCTGTTCATCGTCA-(TAMRA)-3' & \multirow[t]{3}{*}{ XM_425651 } \\
\hline & $\mathrm{F}$ & 5'-CGTCATCATCAAGAGCAAACGC-3' & \\
\hline & $\mathrm{R}$ & 5'-ACAAAACGAGCCAGTGTAAAAGG-3' & \\
\hline \multirow[t]{3}{*}{$\mathrm{IFN} \gamma$} & Probe & 5'-(FAM)-TGGCCAAGCTCCCGATGAACGA-(TAMRA)-3' & \multirow[t]{3}{*}{ Y07922 } \\
\hline & $\mathrm{F}$ & 5'- GTGAAGAAGGTGAAAGATATCATGGA-3' & \\
\hline & $\mathrm{R}$ & 5'-GCTTTGCGCTGGATTCTCA-3' & \\
\hline \multirow[t]{3}{*}{ SMAD-7 } & Probe & 5'-(FAM)-TCCCAGTAAGCCACCACGCACCAGT-(TAMRA)-3' & \multirow[t]{3}{*}{ XM_427238 } \\
\hline & $\mathrm{F}$ & 5'-GCTCTCAGATTCTCAAGTTATTCAGG-3' & \\
\hline & $\mathrm{R}$ & 5'-CCGACCCACACGCATCTTC-3' & \\
\hline \multirow[t]{3}{*}{ TGF $\beta$} & Probe & 5'-(FAM)-ACCCAAAGGTTATATGGCCAACTTCTGCAT-(TAMRA)-3' & \multirow[t]{3}{*}{ M31160 } \\
\hline & $\mathrm{F}$ & 5'-AGGATCTGCAGTGGAAGTGGAT-3'M31160 & \\
\hline & $\mathrm{R}$ & 5'-CCCCGGGTTGTGTGTTGGT-3' & \\
\hline
\end{tabular}

F: forward; R: reverse. 


\section{Results}

\section{Lesions at $21 \mathrm{dpi}$}

The developing MD lymphoma lesions at $21 \mathrm{dpi}$ from resistant and susceptible genotypes are indistinguishable (Fig. 1a, b).

QPCR Based Gene Expression in Whole Tissue and Microscopic Lymphoma Lesions

mRNA expression is presented as 40-mean cycle threshold $\left(\mathrm{C}_{\mathrm{t}}\right)$ values ( \pm standard error of mean [SEM]) (Fig. 2a, b). In whole tissues L6 1 expressed significantly more IL-18, IFN $\gamma$, and GPR-83, but less IL-10 and SMAD-7 mRNA than $\mathrm{L}_{2}$ (Fig. 2a). In microscopic lesions L6 1 produced more IL-4 and less TGF $\beta$, GPR 83 , SMAD-7 and CTLA-4 mRNA (Fig. 2b). IL-2 was below the detectable level of the assay in both whole tissues and in microscopic lesions, and IL-10 and IFN $\gamma$ mRNA were below detectable limits in microscopic lesions of $\mathrm{L}_{1}$ and $\mathrm{L}_{2}$.

\section{GO-Based Modeling}

In the whole tissue samples, our GO-based modelling showed that the tissue microenvironment in both $\mathrm{L} 6_{1}$ and $\mathrm{L}_{2}$ is similarly pro T-reg and pro-inflammatory (Fig. 3a). However, L6 ${ }_{1}$ is also pro Th- 1 and anti Th-2, whereas $\mathrm{L}_{2}$ is anti Th-1 and pro Th-2. At the level of developing microscopic MD-lesions (tumor microenvironment), both
Fig. 2 mRNA expression profiles from kidney from MDVinfected chickens (see M\&M) at 21 dpi for line 6 (resistant to gross lymphomas) and $7_{2}$ (susceptible to gross lymphomas) presented as 40-mean $\mathrm{Ct}$ $( \pm$ SEM, $*=P<0.05)$ at the level whole tissue (a) and microscopic lesions (b)
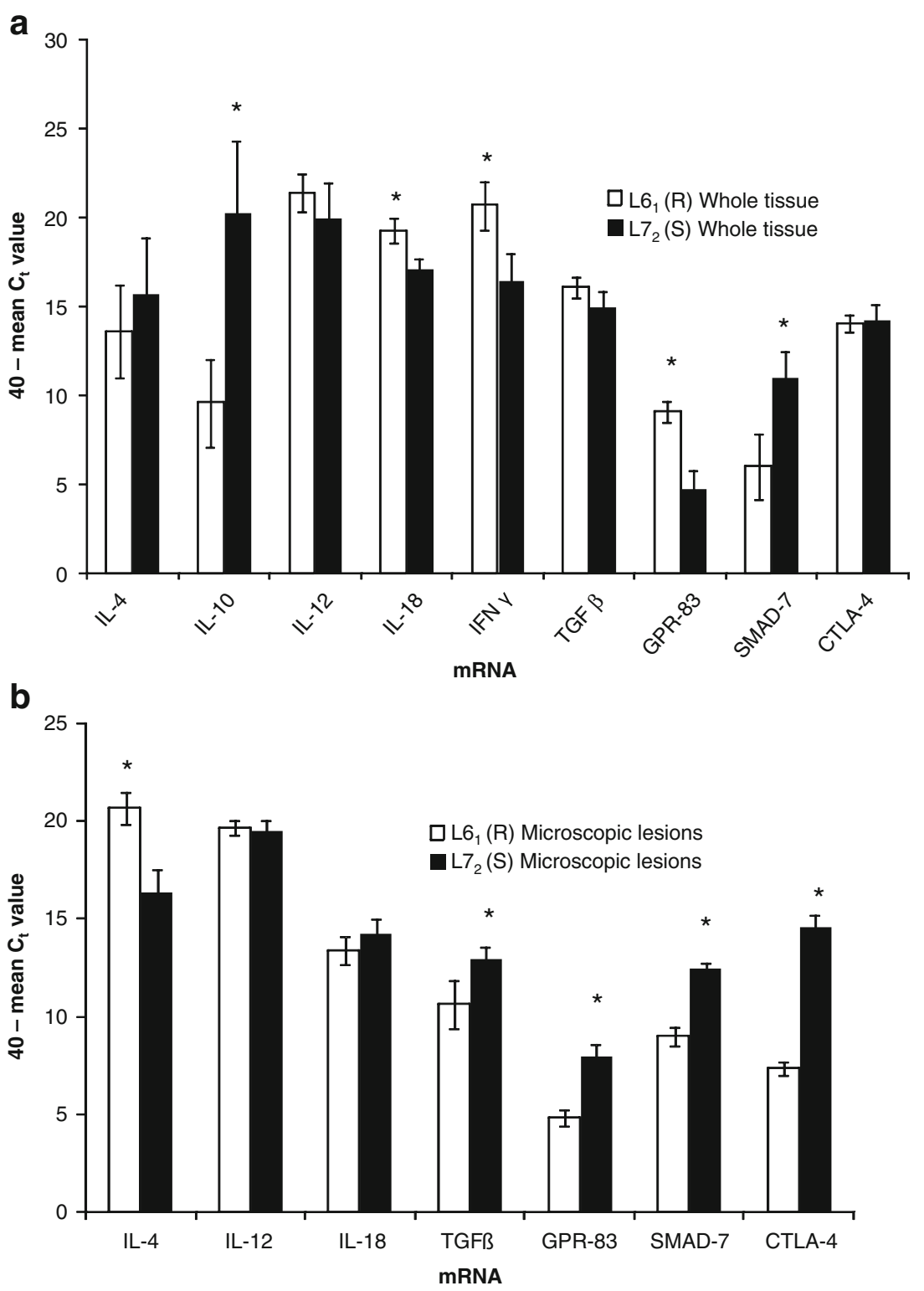
Fig. 3 Gene ontology (GO)based quantitative modeling shows that at the whole tissue level both the resistant $\mathrm{L} 6_{1}$ and the susceptible $\mathrm{L}_{2}$ genotype have a pro T-reg microenvironment but also $\mathrm{L}_{1}$ has a pro Th-1 and anti Th-2 microenvironment while susceptible genotypes have the opposite (a). Microscopic lesions in both $\mathrm{L}_{1}$ and $\mathrm{L} 7_{2}$ have a common phenotype which is pro T-reg, pro Th-2 and anti Th-1 which is antagonistic to cytotoxic $\mathrm{T}$ cell mediated immunity (b)
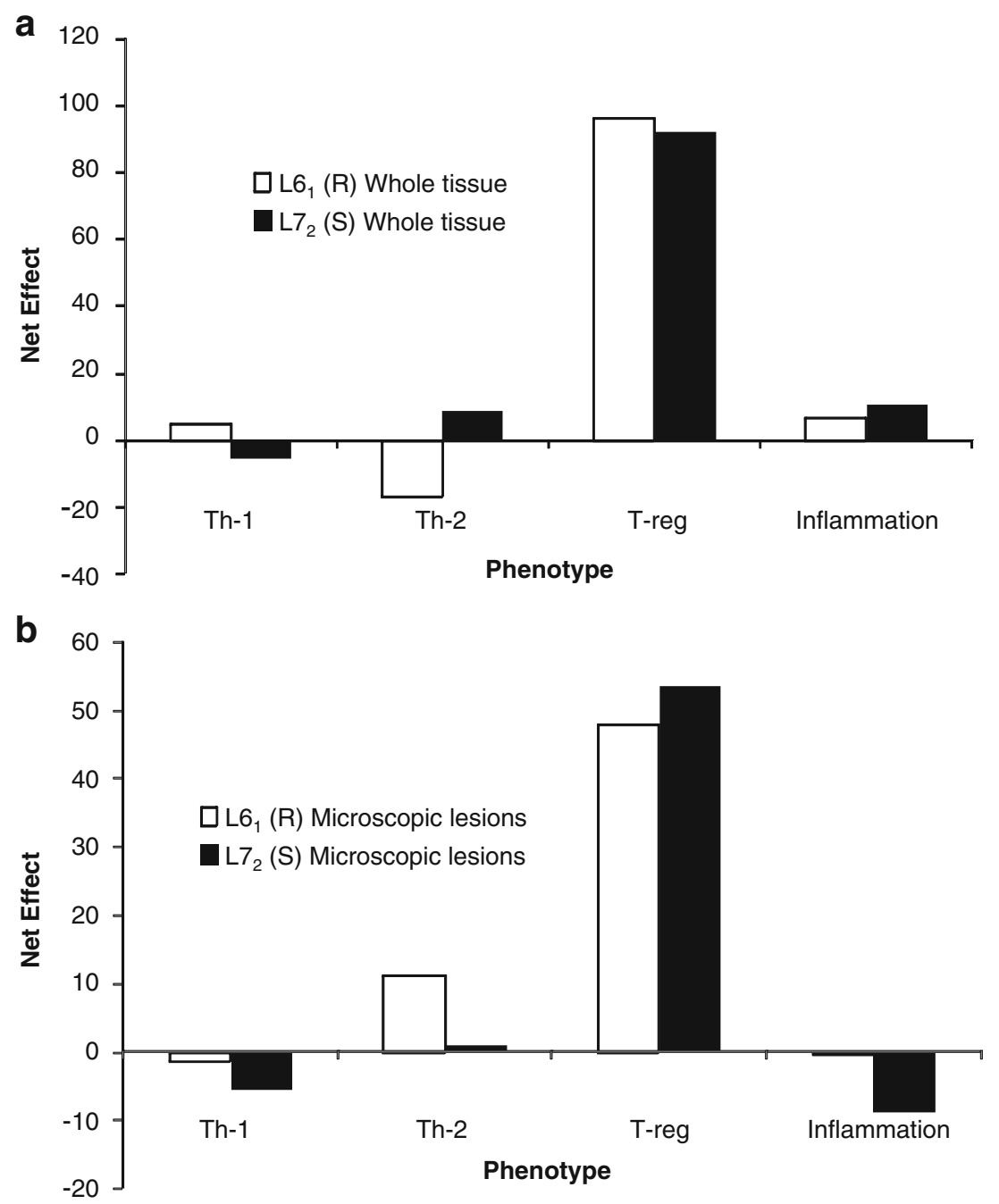

$\mathrm{L}_{1}$ and $\mathrm{L}_{2}$ are similarly high pro T-reg and in contrast to the whole tissues, both $\mathrm{L}_{1}$ and $\mathrm{L}_{2}$ are anti-Th-1, pro Th-2 and anti-inflammatory (Fig. 3b).

\section{Discussion}

Here we have identified the micro-environments of MD tumors at both the whole tissue and microscopic lesion level at the seminal time-point of lymphoma regression and progression in a natural animal model of CD30overexpressing lymphoma. We used mRNA expression data from a panel of defining genes, to perform GO based quantitative hypothesis testing to validate our hypothesis that the tissue micro-environment is compatible with the genotype in which lymphoma regression occurs and not in the genotype with lymphoma progression.

In the MD system the role of cytokines has previously been focused on the virological (rather than neoplastic transformational) stages [20, 23-28]. Xing and Schat [25] proposed that IFN $\gamma$ and nitric oxide (NO) may affect MDV pathogenesis. Kaiser et al. [20], like us, leveraged the power of MD-resistant and -susceptible chicken genotypes to compare cytokine expression in splenocytes and proposed that IL-6 and IL-18 may play an important role in immune the response that could lead to lymphoma progression in susceptible genotypes and what they referred to as the maintenance of latency in resistant genotypes. More recently, Heidari et al. [28] suggested a Th-2 cytokine profile (upregulated IL-4, IL-10, IL-13) in chicken splenocytes in the cytolytic phase of MD. Though splenocytes are one model for studying the immunity and MDV pathogenesis, they may not mimic the MD tissue and tumor microenvironment in non-lymphoid tissues. Regardless, none of the preceding work took the descriptive quantitative genetics to functional modeling.

The increase in IL-18 mRNA in L6 $6_{1}$ that we measured contrasts with Kaiser's data [20] in which there was no increase in IL-18 mRNA in resistant genotypes when compared to age matched uninfected controls. We did not 
detect IL-2 mRNA in either whole tissue or microscopic lesions in both $\mathrm{L} 6_{1}$ and $\mathrm{L} 72$. IL-2 is a crucial immunemodulator cytokine for $\mathrm{T}$ cell proliferation and is required for maintenance of T-reg cells in vivo [29]. However, the MDV "Meq" oncogene binds the IL-2 promoter and represses IL-2 transcription [30] and there are high levels of Meq in MD lymphoma cells [6]; furthermore our previous work has demonstrated less IL-2 mRNA from ex vivo-derived purified $\mathrm{CD} 30^{\mathrm{hi}} \mathrm{MD}$ lymphoma cells compared to $\mathrm{CD} 30^{\text {lo }}$ cells [5]. Our IL-2 data again contrasts with that of Kaiser et al. [20] who identified more IL-2 mRNA in L7 splenocytes at 21 dpi compared to uninfected controls, but the IL-2 mRNA in the spleen is probably derived from activated, rather than transformed, $\mathrm{T}$ cells. Also, the high levels of IL-4 in both L6 $6_{1}$ and L7 $7_{2}$ would be predicted to directly suppress IL-2 transcription [28].GPR83 is selectively upregulated in T-reg cells of both humans and mice and is critically involved in mediating T-reg functions as well as in development of induced T-reg cells [11]. However, recently $\mathrm{Lu}$ et al. [31] suggested that GPR83 is dispensable for T-reg functions. Though the role of GPR-83 in T-reg biology is questioned in one publication, it is still generally accepted to be a selective marker for T-reg cells and so we included it our work here. SMAD 7 is the member of the inhibitory type of SMADs which acts in a negative feedback for TGF $\beta$ signaling. Since the expression of inhibitory SMADs is induced by TGF $\beta$ [32] increased SMAD 7 expression suggests an increase in the TGF $\beta$ expression which triggers this negative feedback loop [33]. This is in accordance with our data, which show an increase in TGF $\beta$ and SMAD 7 mRNA expression in $\mathrm{L}_{2}$ tumor microenvironment.

Our GO-based modeling demonstrates that a T-reg phenotype predominates in both $\mathrm{L}_{1}$ and $\mathrm{L} 7_{2}$ at both whole tissue and microscopic lesion levels (Fig. 3a and b). The whole tissue consists of a heterogeneous mixture of large numbers of transformed cells which are transcriptionally very active and normal immune and non immune kidney cells. We propose that the T-reg phenotype is contributed by the transformed cells and the relatively weaker Th-1 phenotype in $\mathrm{L}_{1}$ and Th-2 phenotype in $\mathrm{L} 7_{2}$ are indicative of host immune responses from non transformed cells in the tissues. When the mRNA from the surrounding tissue (tissue microenvironment) is removed both, $\mathrm{L} 6_{1}$ and $\mathrm{L} 7_{2}$ have a similar phenotype (i.e. pro-T-reg, anti Th-1, proTh-2 and anti-inflammatory) i.e. antagonistic to CTL. Our result is consistent with the cellular profiles previously identified in MD lymphomas by immunohistochemistry [8] and flow cytometry [6], as well as evidence of specific CTL anti-tumor immunity [3,9], and together; support our hypothesis that in $\mathrm{L}_{1}$ the tissue microenvironment is congruent with CTL mediated immunity leading to lymphoma regression while a T-reg/Th-2 phenotype is dominant in $\mathrm{L}_{2}$ which is consistent with continued lymphomagenesis.

Both $\mathrm{L} 6_{1}$ and $\mathrm{L} 7_{2}$ have a pro inflammatory phenotype in whole tissues, inflammation is causative factor in carcinogenesis in general [34] and inflammation is linked to various types of lymphomas $[34,35]$. The inducible transcription factor NF-kappaB is a pivotal regulator of genes involved in immune-inflammatory pathways, cell cycle progression and inhibition of apoptosis promoting carcinogenesis in mice and humans [36]. The MDV Meq protein binds the $\mathrm{CD} 30$ promoter and enhances CD30 transcription [3], which in turn can activate the NF-kappaB transcription factor via the $\mathrm{CD} 30$-tumor necrosis factor receptor associated factor (TRAF) (1,2,3)-NF-kappaB signaling pathway [37]. The high amounts of Meq protein, over-expression of CD30 in transformed cells in all genotypes (regardless of MD-susceptibility or -resistance) in the first week after MDV infection [6] and the proinflammatory profile in both $\mathrm{L}_{1}$ and $\mathrm{L} 7_{2}$ in our current work together suggest that the genetic pathways of inflammation are also common to MD.

The tumor microenvironment is critical in development and maintenance of lymphoma generally [38] and this is also true for MD [6]. A complex network of cytokines and cell-to-cell contact mediated interactions between the transformed cells and surrounding reactive infiltrate can lead to further proliferation of neoplastic cells [38]. In classical Hodgkin's lymphoma (cHL), cytokine production by the transformed cells and the surrounding reactive infiltrating cells acts in autocrine and paracrine ways to result in the survival and proliferation of transformed cells and the maintenance of immunosuppressive microenvironment [39]. Aberrant activation of the STAT pathway is a postulated mechanism employed by neoplastic cells in HL derived cell lines to escape cell death [40] and the reactive infiltrate in $\mathrm{HL}$ is primarily comprised of Th-2 type of cells enriched in T-reg cells, though not always with a classical Th-2 type cytokine profile [38, 41]. These reactive cells express CTLA-4 and are anergic (which may be due to increased TGF $\beta$ and IL-10 expression). In human EpsteinBarr virus (EBV) positive tumors, genetically engineered TGF $\beta$ resistant CTLs had better antitumor activity than unmodified CTLs, suggesting the inhibitory role of TGF $\beta$ [42]. Also, EBV-infected HL transformed cells express the Epstein-Barr nuclear antigen-1 (EBNA-1) gene which upregulates the expression of chemokine (C-C motif) ligand (CCL20) binding, which is a strong chemoattractant of T-regs to the tumor microenvironment [43]. Alvaro et al. [44, 45] used the cellular composition of HL tumor microenvironment as a prognostic marker and suggested that a low number of cytotoxic $\mathrm{T}$ cells in reactive infiltrate correlate with increase in anti-apoptotic mechanisms in neoplastic cells. Wahlin et al. [46] proposed that the presence of more 
of CD8+ T cells is a positive prognostic marker in human follicular lymphoma. Overall our results here and previously [5] suggest that the initial latently transformed minority cells which are $\mathrm{CD} 4+\mathrm{CD} 30^{\mathrm{hi}}$ are of T-reg phenotype and these cells induce the infiltrating $\mathrm{CD} 4+\mathrm{T}$ cells to the T-reg phenotype in both $\mathrm{L} 6_{1}$ and $\mathrm{L} 7_{2}$. In $\mathrm{L}_{1}$ a Th-1 tissue microenvironment would support $\mathrm{CD} 8+\mathrm{T}$ cell-mediated immunity and $\mathrm{CD} 8+\mathrm{T}$ cells have been observed in these lesions previously (8). Furthermore, IFN $\gamma$-secreting CD4+ T cells could recruit macrophages (also previously described in resistant MD lines [8]), induce MHC class I up regulation on the target transformed T-cells and promote restricted CD8+ CTL cells [47]. The mechanisms by which such a Th- 1 could "over-ride" the T-reg type response within the neoplastic lesions themselves is unclear, but the Th-1 bias we observed is a clear distinction between the resistant and the susceptible MHC congenic lines. The strength of the MD system for understanding how the tissue and tumor microenvironment effects genetically-determined lymphoma regression or progression, and which we took advantage of, is that it is a natural system in the context of a non-manipulated immune environment with predictable pathogenesis.

Acknowledgements This paper was supported by USDA NRI 200635204-16549. We would like to thank Dr Karen Coats, Dr. Fiona McCarthy, Dusan Kunec and two anonymous reviewers for critically reading manuscript and making valuable suggestions.

Open Access This article is distributed under the terms of the Creative Commons Attribution Noncommercial License which permits any noncommercial use, distribution, and reproduction in any medium, provided the original author(s) and source are credited.

\section{References}

1. Jemal A, Siegel R, Ward E et al (2007) Cancer statistics, 2007. CA Cancer J Clin 57:43-66

2. Institute NC (2007) The NCI strategic plan for leading the nation to eliminate the suffering and death due to cancer. Available via: http://strategicplan.nci.nih.gov/pdf/nci_2007_strategic_plan.pdf [cited 05/29 2008]

3. Burgess SC, Young JR, Baaten BJ et al (2004) Marek's disease is a natural model for lymphomas overexpressing Hodgkin's disease antigen (CD30). Proc Natl Acad Sci USA 101:13879-13884

4. Buza JJ, Burgess SC (2007) Modeling the proteome of a Marek's disease transformed cell line: a natural animal model for CD30 overexpressing lymphomas. Proteomics 7:1316-1326

5. Shack LA, Buza JJ, Burgess SC (2008) The neoplastically transformed (CD30(hi)) Marek's disease lymphoma cell phenotype most closely resembles T-regulatory cells. Cancer Immunol Immunother 57:1253-1262

6. Burgess SC, Davison TF (2002) Identification of the neoplastically transformed cells in Marek's disease herpesvirus-induced lymphomas: recognition by the monoclonal antibody AV37. J Virol 76:7276-7292

7. Abdelrazeq AS (2007) Spontaneous regression of colorectal cancer: a review of cases from 1900 to 2005. Int J Colorectal Dis 22:727-736
8. Burgess SC, Basaran BH, Davison TF (2001) Resistance to Marek's disease herpesvirus-induced lymphoma is multiphasic and dependent on host genotype. Vet Pathol 38:129-142

9. Burgess SC, Venugopal KN (2002) Chapter VII: Anti-tumor immune responses after infection with the Marek's disease and Avian Leukosis Oncogenic viruses of poultry. In: Mathew T (ed) Advances in medical \& veterinary virology, immunology and epidemiology modern concepts of immunology in veterinary medicine: poultry immunology. Thajema, West Orange, NJ, USA, pp 236-291

10. O'Garra A, Arai N (2000) The molecular basis of T helper 1 and $\mathrm{T}$ helper 2 cell differentiation. Trends Cell Biol 10:542-550

11. Hansen W, Loser K, Westendorf AM et al (2006) G proteincoupled receptor 83 overexpression in naive CD4+CD25- T cells leads to the induction of Foxp3+ regulatory $\mathrm{T}$ cells in vivo. $\mathrm{J}$ Immunol 177:209-215

12. Jarnicki AG, Lysaght J, Todryk S et al (2006) Suppression of antitumor immunity by IL-10 and TGF-beta-producing $\mathrm{T}$ cells infiltrating the growing tumor: influence of tumor environment on the induction of CD4+ and CD8+ regulatory T cells. J Immunol 177:896-904

13. Pfoertner S, Jeron A, Probst-Kepper M et al (2006) Signatures of human regulatory $\mathrm{T}$ cells: an encounter with old friends and new players. Genome Biol 7:R54

14. Kabelitz D, Wesch D, Oberg HH (2006) Regulation of regulatory T cells: role of dendritic cells and toll-like receptors. Crit Rev Immunol 26:291-306

15. Liu H, Leung BP (2006) CD4+CD25+ regulatory T cells in health and disease. Clin Exp Pharmacol Physiol 33:519-524

16. Mizobuchi T, Yasufuku K, Zheng Y et al (2003) Differential expression of Smad7 transcripts identifies the CD4+CD45RChigh regulatory $\mathrm{T}$ cells that mediate type $\mathrm{V}$ collagen-induced tolerance to lung allografts. J Immunol 171:1140-1147

17. Dominitzki S, Fantini MC, Neufert C et al (2007) Cutting edge: trans-signaling via the soluble IL-6R abrogates the induction of FoxP3 in naive CD4+CD25 $\mathrm{T}$ cells. J Immunol 179:2041-2045

18. Rothwell L, Young JR, Zoorob R et al (2004) Cloning and characterization of chicken IL-10 and its role in the immune response to Eimeria maxima. J Immunol 173:2675-2682

19. Kaiser MG, Cheeseman JH, Kaiser P et al (2006) Cytokine expression in chicken peripheral blood mononuclear cells after in vitro exposure to Salmonella enterica serovar Enteritidis. Poult Sci 85:1907-1911

20. Kaiser P, Underwood G, Davison F (2003) Differential cytokine responses following Marek's disease virus infection of chickens differing in resistance to Marek's disease. J Virol 77:762-768

21. Eldaghayes I, Rothwell L, Williams A et al (2006) Infectious bursal disease virus: strains that differ in virulence differentially modulate the innate immune response to infection in the chicken bursa. Viral Immunol 19:83-91

22. McCarthy FM, Bridges SM, Burgess SC (2007) Going from functional genomics to biological significance. Cytogenet Genome Res 117:278-287

23. Schat KA, Xing Z (2000) Specific and nonspecific immune responses to Marek's disease virus. Dev Comp Immunol 24:201221

24. Xing Z, Schat KA (2000) Inhibitory effects of nitric oxide and gamma interferon on in vitro and in vivo replication of Marek's disease virus. J Virol 74:3605-3612

25. Xing Z, Schat KA (2000) Expression of cytokine genes in Marek's disease virus-infected chickens and chicken embryo fibroblast cultures. Immunology 100:70-76

26. Abdul-Careem MF, Hunter BD, Parvizi P et al (2007) Cytokine gene expression patterns associated with immunization against Marek's disease in chickens. Vaccine 25:424-432 
27. Quere P, Rivas C, Ester K et al (2005) Abundance of IFN-alpha and IFN-gamma mRNA in blood of resistant and susceptible chickens infected with Marek's disease virus (MDV) or vaccinated with turkey herpesvirus; and MDV inhibition of subsequent induction of IFN gene transcription. Arch Virol 150:507-519

28. Heidari M, Zhang HM, Sharif S (2008) Marek's disease virus induces Th-2 activity during Cytolytic Infection. Viral Immunol

29. Antony PA, Restifo NP (2005) CD4+CD25+ T regulatory cells, immunotherapy of cancer, and interleukin-2. J Immunother $28: 120-128$

30. Levy AM, Izumiya Y, Brunovskis P et al (2003) Characterization of the chromosomal binding sites and dimerization partners of the viral oncoprotein Meq in Marek's disease virus-transformed T cells. J Virol 77:12841-12851

31. Lu LF, Gavin MA, Rasmussen JP et al (2007) G protein-coupled receptor 83 is dispensable for the development and function of regulatory T cells. Mol Cell Biol 27:8065-8072

32. Miyazono K, ten Dijke P, Heldin CH (2000) TGF-beta signaling by Smad proteins. Adv Immunol 75:115-157

33. Rubtsov YP, Rudensky AY (2007) TGFbeta signalling in control of T-cell-mediated self-reactivity. Nat Rev Immunol 7:443-453

34. Marx J (2004) Cancer research. Inflammation and cancer: the link grows stronger. Science 306:966-968

35. Hold GL, El-Omar ME (2008) Genetic aspects of inflammation and cancer. Biochem J 410:225-235

36. Okamoto T, Sanda T, Asamitsu K (2007) NF-kappa B signaling and carcinogenesis. Curr Pharm Des 13:447-462

37. Horie R, Watanabe T (1998) CD30: expression and function in health and disease. Semin Immunol 10:457-470

38. Herreros B, Sanchez-Aguilera A, Piris MA (2008) Lymphoma microenvironment: culprit or innocent? Leukemia 22:49-58
39. Skinnider BF, Mak TW (2002) The role of cytokines in classical Hodgkin lymphoma. Blood 99:4283-4297

40. Cochet O, Frelin C, Peyron JF et al (2006) Constitutive activation of STAT proteins in the HDLM-2 and L540 Hodgkin lymphoma-derived cell lines supports cell survival. Cell Signal 18:449-455

41. Jurianz K, von Hoegen P, Schirrmacher V (1999) Immunological and molecular characterization of an aggressive murine lymphoma variant: modulation in vitro and in vivo. Int $\mathrm{J}$ Oncol 15:71-79

42. Foster AE, Dotti G, Lu A et al (2008) Antitumor activity of EBVspecific $\mathrm{T}$ lymphocytes transduced with a dominant negative TGF-beta receptor. J Immunother

43. Baumforth KR, Birgersdotter A, Reynolds GM et al (2008) Expression of the Epstein-Barr Virus-Encoded Epstein-Barr Virus Nuclear Antigen 1 in Hodgkin's Lymphoma Cells Mediates Up-Regulation of CCL20 and the Migration of Regulatory T Cells. Am J Pathol

44. Alvaro T, Lejeune M, Garcia JF et al (2008) Tumor-infiltrated immune response correlates with alterations in the apoptotic and cell cycle pathways in Hodgkin and Reed-Sternberg cells. Clin Cancer Res 14:685-691

45. Alvaro T, Lejeune M, Salvado MT et al (2006) Immunohistochemical patterns of reactive microenvironment are associated with clinicobiologic behavior in follicular lymphoma patients. J Clin Oncol 24:5350-5357

46. Wahlin BE, Sander B, Christensson B et al (2007) CD8+ T-cell content in diagnostic lymph nodes measured by flow cytometry is a predictor of survival in follicular lymphoma. Clin Cancer Res 13:388-397

47. Chamoto K, Kosaka A, Tsuji T et al (2003) Critical role of the Th1/Tc1 circuit for the generation of tumor-specific CTL during tumor eradication in vivo by Th1-cell therapy. Cancer Sci 94:924-928 